\title{
Increased risk profile in the treatment of patients with symptomatic degenerative aortic valve stenosis over the last 10 years
}

\author{
Jakub Baran ${ }^{1}$, Jakub Podolec ${ }^{1}$, Marek T. Tomala ${ }^{1}$, Bartłomiej Nawrotek ${ }^{1}$, tukasz Niewiara ${ }^{1}$, \\ Andrzej Gackowski ${ }^{2}$, Tadeusz Przewłocki ${ }^{1}$, Krzysztof Żmudka ${ }^{1}$, Anna Kabłak-Ziembicka ${ }^{1}$ \\ ${ }^{1}$ Department of Interventional Cardiology, Institute of Cardiology, Jagiellonian University Medical College, The John Paul II Hospital, Krakow, \\ Poland \\ 2Department of Coronary Disease and Heart Failure, Institute of Cardiology, Jagiellonian University Medical College, The John Paul II \\ Hospital, Krakow, Poland
}

Adv Interv Cardiol 2018; 14, 3 (53): 276-284

DOI: https://doi.org/10.5114/aic.2018.78331

\begin{abstract}
A bstract
Introduction: Currently, Cardiology Centres are overfilled with patients with degenerative aortic valve stenosis (DAS), usually eldery, with severe concommittant comorbidities, who are referred for further decisions and possible intervention.

Aim: To evaluate changes in the risk profile of patients with severe DAS admitted to the cardiology department a decade ago compared with patients currently being admitted.

Material and methods: We retrospectively evaluated all patients admitted with confirmed severe DAS, hospitalized during 2005-2006 (group I: 140 patients) and in 2016 (group II: 152 patients), admitted for aortic valve intervention. A standard transthoracic echocardiogram, cardiovascular symptom and risk factor distribution, perioperative risk with the logistic EuroSCORE II and STS mortality scores were obtained.

Results: Patients in group II were significantly older $(p<0.001)$, had more cardiovascular risk factors, and more often presented with atrial fibrillation ( $27 \%$ vs. $11.4 \%, p=0.001$ ), renal impairment ( $34.9 \%$ vs. $22.8 \% ; p=0.024)$, severe lung disease $(17.1 \%$ vs. $2.1 \%, p<0.001)$, and extracardiac arteriopathy ( $40.1 \%$ vs. $17.8 \%, p<0.001)$. The aortic valve area (AVA) $(p=0.356)$, mean-transvalvular pressure gradient $(p=0.215)$, and left ventricular ejection fraction $(p=0.768)$ were similar in both groups. However, the prevalence of pulmonary hypertension, severe mitral regurgitation, and low-flow, low-gradient DAS were 3.1-, 8.4- and 1.84-fold more frequent in group II than group I. The percentages of subjects with EuroSCORE II and STS scores $\geq 4 \%$ in 2005-2006 were $7.1 \%$ and $6.4 \%$, as compared to $27 \%$ and $26.3 \%$ in 2016 (both $p<0.001$ ). $22 \%$ of patients in 2016, as compared to $31 \%$ in $2005 / 2006$, were considered ineligible for DAS intervention.

Conclusions: In just a decade, the risk profile of patients admitted with DAS has increased hugely, mainly due to older age, accumulation of comorbidities and more advanced disease at presentation. Although transcatheter aortic valve intervention has expanded the indications for intervention in high-risk patients, the number of patients disqualified from interventional treatment remains high.
\end{abstract}

Key words: degenerative aortic valve stenosis, transcatheter aortic valve intervention, aortic valve replacement, risk assessment, EuroSCORE II, STS score.

Su m m a ry

Currently, Cardiology Centers are overfilled with patients with degenerative aortic valve stenosis, who are referred for further decisions and possible intervention. In this study we evaluated differences in clinical performance, associated comorbidities, echocardiographic findings, and the surgical mortality scores in patients referred to intervention currently and 10 years ago. Also, we compared the proportion of patients reffered to invasive treatment and considered ineligible in years 2005-2006 vs. in 2016.

\section{Corresponding author:}

Prof. Anna Kabłak-Ziembicka MD, PhD, Department of Interventional Cardiology, Institute of Cardiology, Jagiellonian University Medical College, The John Paul II Hospital, 80 Prądnicka St, 31-202 Krakow, Poland, phone: +48 1261435 01, e-mail: kablakziembicka@op.pl Received: 24.04.2018, accepted: 17.06.2018. 


\section{Introduction}

Degenerative aortic valve stenosis (DAS) most commonly affects elderly patients [1,2] and its prevalence is estimated to be $2-7 \%$ in people over the age of $65[3,4]$. As a result of global population aging, a rapid increase in the incidence of DAS is noted $[5,6]$.

Aortic valve degeneration is characterized by systematic valve calcification and narrowing, and several risk factors of stenosis progression have been proposed [3-10]. Rapid DAS progression may be associated with the extent of aortic valve and muscle calcifications, the disease activity assessed with positron emission tomography, or CT calcium scoring, or high inflammatory status (CRP, RANTES), also in patients with diabetes, concomitant coronary artery disease, or hemodialysis [7-9]. However, the progression is individually variable and cannot be easily predicted [7-10].

In the beginning, it is typically associated with a peak and mean transvalvular pressure gradient increase, left ventricular hypertrophy, and left atrial enlargement. Along with further DAS deterioration, other cardiac disorders such as left ventricular dysfunction, mitral valve insufficiency, atrial arrhythmias, pulmonary hypertension, and right ventricular dysfunction worsen a patient's prognosis [10]. Therapeutic decision-making in the elderly with advanced, complicated DAS, accompanied by other cardiac and extracardiac problems, is difficult. At the time of patient referral for invasive intervention, the procedure-related 30-day mortality risk, using the EuroSCORE II and Society of Thoracic Surgeon risk score (STS), is frequently unacceptably high [11-14].

Echocardiography plays the principal role, not only in DAS diagnosis, but more importantly, is crucial in cardiac risk monitoring of congestive heart failure and sudden cardiac death $[10,15,16]$. The complementary role of biomarkers in the process of evaluation of DAS still requires further investigation [17]. If complicated DAS occurs, it is associated with a rapidly increasing risk of heart failure and death in patients managed conservatively, as well as difficult decisions on further management due to perioperative mortality and morbidity risk.

As per current guidelines, intervention for DAS is recommended in patients with symptomatic severe DAS (level of evidence: IB) and in patients with moderate DAS referred for coronary artery bypass or ascending aorta surgery (level of evidence: Ila-C) [11]. Furthermore, AVR is recommended in asymptomatic patients with severe DAS and unexplained left ventricular dysfunction (LVEF $<50 \%$ ) (level of evidence: IC), as well as an abnormal result of the exercise test (level of evidence: IC).

\section{Aim}

The main objective of the present study was to compare the risk profile and comorbidities affecting perioperative risk in patients with symptomatic moderate-to-se- vere DAS referred for aortic stenosis treatment in 2005-2006, as compared to patients admitted in 2016.

\section{Material and methods}

The study group consisted of 292 patients with confirmed symptomatic severe DAS (defined as an aortic valve area $<1.0 \mathrm{~cm}^{2}$ from the continuity equation) referred to our department for aortic valve stenosis intervention.

Group I consisted of 140 consecutive patients (87 men, 53 women), mean age: $64.1 \pm 8.9$ years (range: $40-83$ ), admitted to the hospital between January 2005 and December 2006.

Group II comprised 152 consecutive patients (75 men, 77 women), mean age: $73.1 \pm 9.6$ years (range: $47-91$ ), admitted to the hospital between January 2016 and December 2016.

All subjects were evaluated, including an assessment of clinical symptoms with the New York Heart Association (NYHA) Classification and the Canadian Cardiovascular Society Grading System for exertion-induced angina (CCS), and the distribution of major cardiovascular risk factors (gender, age, hypertension, diabetes mellitus type II, hyperlipidemia).

Transthoracic echocardiography, carotid ultrasonography, and coronary angiography were performed.

Perioperative risk was assessed with the EuroSCORE II and STS scores.

The study protocol was consistent with the requirements of the Helsinki Declaration, and approved by the local Institutional Ethics Committee. All subjects gave informed consent for participation in the study.

Coronary angiography was performed in all patients using COROSCOP (Siemens), equipped with Quantcor QCA V 2.0 quantitative coronary analysis software. Patients with at least one lesion $\geq 50 \%$ reduction in lumen diameter within the main branches of the coronary arteries were considered to have significant CAD.

\section{Echocardiographic study}

All patients underwent a complete echocardiographic study in compliance with the guidelines of the European Association of Cardiovascular Imaging [16]. The peak and mean gradient through the aortic valve, the aortic valve area (AVA), left ventricular ejection fraction (LVEF), grading of mitral valve insufficiency, right ventricular dysfunction, and pulmonary hypertension $(\mathrm{PH})$ grading were calculated in groups I and II.

\section{Carotid artery ultrasonography}

High-resolution B-Mode, color Doppler, and pulse Doppler ultrasound of both carotid arteries were performed with an ultrasound machine (TOSHIBA APLIO) featuring a linear-array 5-10 MHz transducer. The degree of carotid stenosis was assessed through an increase in the peak systolic and end-diastolic velocities (according 
to the Bluth criteria) [18]. The carotid artery stenosis was considered significant ( $>50 \%$ lumen reduction) if peak systolic velocity was $>1.3 \mathrm{~m} / \mathrm{s}$, end-diastolic velocity $>0.4 \mathrm{~m} / \mathrm{s}$, and lumen reduction exceeded $70 \%$ on transverse scans. Experienced sonographers who had no prior knowledge of the subject's clinical and angiographic characteristics obtained all scans. The importance of carotid artery ultrasonography in DAS has been previously demonstrated $[19,20]$.

\section{Perioperative risk calculators: EuroSCORE II and STS score}

STS score - the Society of Thoracic Surgeons-Predicted Risk of Mortality score (STS-PROM) and the European System for Cardiac Operative Risk Evaluation (EuroSCORE) model (additive and logistic) were used to evaluate the risk in all patients [12, 13].

Two experienced cardiologists working together assessed perioperative risk using calculators which are freely available online: STS score (http://riskcalc.sts.org/ stswebriskcalc/\#/calculate) and EuroSCORE II (http:// www.euroscore.org/calc.html). Variables included in both scores were judged according to guidelines supplied to databases.

Analyzed variables included in the calculation of scores were defined as follows:

Data on disabling ischemic stroke were obtained from a stroke unit and sourced from available medical documentation. Brain imaging was obtained either with computed tomography (CT) or magnetic resonance imaging (MRI).

Data on chronic lung disease were collected from available medical documentation and from results of pulmonary function tests.

Estimated glomerular filtration rate (eGFR) was calculated using the MDRD formula and for the EuroSCORE II calculator using the Cockcroft-Gault formula. A history of peripheral artery disease including claudication (upper and lower extremities, renal, mesenteric, and abdominal aortic systems) was collected from the patient's medical history. Data on previous cardiac interventions, procedure urgency, critical perioperative state, and concomitant cardiac surgery were obtained from medical documentation.

\section{Statistical analysis}

Continuous variables are presented as mean \pm SD, categorical variables are expressed as frequencies and percentages. Means of analyzed parameters across groups were tested with the analysis of variance (ANOVA) test and frequencies were compared using the $\chi^{2}$ test for independence.

The normal distribution of studied variables was determined using the Shapiro-Wilk test. Differences between mean values of echocardiographic parameters were verified using the Mann-Whitney $U$ test as the distribution of variables was found not to be normal. The
$U$ test results were presented as the median and interquartile range.

Statistical analyses were performed using Statistica 12.0 software. Statistical significance was assumed at $p<0.05$.

\section{Results}

\section{Basic characteristics of patients}

Baseline characteristics of study participants are shown in Table I. Subjects in group II, when compared with those in group I, were significantly older. In comparison to group I, group II patients were more often females and showed a significantly increased prevalence of classic cardiovascular risk factors such as hypertension, diabetes mellitus, and hyperlipidemia (Table I). Group I patients, when compared to group II patients, presented more frequently with symptoms assessed as grade 2 to 4 according to the NYHA classification, but reported fewer symptoms according to the CCS scale (Table I). However, there was no significant difference with respect to prevalence of symptoms in class 4, both according to the NYHA as well as the CCS classification (Table I).

\section{Echocardiography results}

A comparison of echocardiographic characteristics is displayed in Table II. On echocardiography, there were no significant differences between groups with respect to LVEF $(57.5 \pm 12.1 \%$, median $60 \%$ vs. $55 \pm 12.1 \%$, median $60 \%, p=0.768)$, mean aortic valve gradients (48.6 \pm 19.9 vs. $46.2 \pm 15.6 \mathrm{~mm} \mathrm{Hg}, p=0.215)$, and the AVA ( $0.87 \pm 0.3$ vs. $0.90 \pm 0.32 \mathrm{~cm}^{2}, p=0.356$ ) (Table II). Peak aortic gradient was higher in group I vs. group II (82.3 \pm 27.7 vs. 76 $\pm 25.5 \mathrm{~mm} \mathrm{Hg}, p=0.05$ ).

Low-flow-low-gradient DAS was more frequent in group II vs. group I subjects ( $11.8 \%$ vs. $6.4 \%, p=0.037)$. $\mathrm{PH}$ was more frequent in group II vs. group I subjects ( $27 \%$ vs. $8.6 \%, p<0.001)$. Severe mitral regurgitation was more frequent in group II vs. group I subjects (5.9\% vs. $0.7 \%, p=0.015$ ).

\section{Perioperative risk factor distribution and comorbidities included in STS score and EuroSCORE II}

Risk factors and comorbidities influencing perioperative risk scores are shown in Table III.

In group II vs. group I, female subjects were more frequent $(50.7 \%$ vs. $37.9 \%, p=0.028)$. Extracardiac arteriopathy $(40.1 \%$ vs. $17.8 \%, p<0.001)$, renal dysfunction (34.9\% vs. $22.8 \%, p=0.024)$, atrial fibrillation $(27 \%$ vs. $11.4 \%, p=0.001)$, and severe chronic lung disease (17.1\% vs. $2.1 \%, p<0.001)$ were all more prevalent in group II vs. group I patients. The prevalence of coronary artery disease (at least one major coronary artery with lumen reduction exceeding 50\%) was similar in both 
Table I. Baseline characteristics of study participants

\begin{tabular}{|c|c|c|c|}
\hline Parameter & DAS patients $2005 / 2006(n=140)$ & DAS patients $2016(n=152)$ & $P$-value \\
\hline \multicolumn{4}{|l|}{ Demographic data: } \\
\hline Age, mean $\pm S D^{* \#}[$ years] & $64.1 \pm 8.9$ & $73.1 \pm 9.6$ & $<0.001$ \\
\hline Median (Q1 : Q3) & $65(57: 71)$ & $74(67: 81)$ & \\
\hline Female, $n(\%)^{\star \#}$ & $53(37.9)$ & $77(50.7)$ & 0.028 \\
\hline \multicolumn{4}{|l|}{ Clinical symptoms, $n$ (\%): } \\
\hline $\mathrm{NYHA} \geq \|^{* \#}$ & $135(96.4)$ & $129(84.9)$ & 0.001 \\
\hline $\mathrm{NYHA}=I \mathrm{~V}^{* \#}$ & $4(2.9)$ & $4(2.6)$ & 0.906 \\
\hline $\mathrm{CCS} \geq \|^{*}$ & $36(25.7)$ & $58(41.4)$ & 0.023 \\
\hline $\mathrm{CCS}=I \mathrm{~V}^{* \#}$ & $1(0.7)$ & $3(2.0)$ & 0.355 \\
\hline \multicolumn{4}{|l|}{ Risk factors, $n(\%)$ : } \\
\hline Hypertension* & $96(68.6)$ & $148(97.3)$ & $<0.001$ \\
\hline Diabetes* & $25(17.8)$ & $54(35.5)$ & 0.001 \\
\hline On insulin*\# & $3(2.1)$ & $15(9.9)$ & 0.006 \\
\hline Dyslipidemia & $111(79.3)$ & $150(98.6)$ & $<0.001$ \\
\hline$C A D^{* \#}$ & $59(42.1)$ & $71(46.7)$ & 0.433 \\
\hline Previous MI*\# & $12(8.6)$ & $25(16.4)$ & 0.043 \\
\hline Previous $\mathrm{PCl}^{\star}$ & $6(9.2)$ & $39(25.6)$ & $<0.01$ \\
\hline \multicolumn{4}{|l|}{ Laboratory results, mean \pm SD: } \\
\hline LDL cholesterol [mmol/I] & $3.4 \pm 1.00$ & $2.7 \pm 1.00$ & $<0.001$ \\
\hline Creatinine $[\mu \mathrm{mol} / \mathrm{l}]$ & $87.7 \pm 21.2$ & $88.4 \pm 23.4$ & 0.801 \\
\hline Hemoglobin [g/dl] & $13.7 \pm 1.6$ & $13.1 \pm 1.6$ & 0.435 \\
\hline
\end{tabular}

*Parameters included in STS score, "parameters included in EurOSCORE II.

groups ( $42.1 \%$ vs. $46.7 \%, p=0.433)$, while rates of previous myocardial infarction ( $16.4 \%$ vs. $8.6 \%, p=0.043$ ) and $\mathrm{PCl}(25.6 \%$ vs. $9.2 \%, p<0.01)$ were more frequent in group II vs. group I subjects.

\section{Perioperative risk scores}

The mean perioperative mortality risk scores in group II were significantly higher than those in group I (EuroSCORE II: $3.52 \pm 3.97 \%$ vs. $1.26 \pm 2.8 \% p<0.001$; STS mortality score: $3.14 \pm 2.7 \%$ vs. $1.12 \pm 2.43$; $p<0.001$ ) (Figure $1 \mathrm{~A}$ ).

The prevalence of subjects with high perioperative mortality risk $\geq 4 \%$ was significantly higher in group II than group I. This was with respect to the EuroSCORE II: $41(27 \%)$ vs. $10(7.1 \%)(p<0.001)$ and STS: $40(26.3 \%)$ vs. $9(6.4 \%)(p<0.001)$ (Figure $1 \mathrm{~B})$.

\section{Treatment options}

In the year $2005 / 2006,69 \%$ of patients were referred for AVR, while $31 \%$ of subjects were given optimal med- ical treatment (OMT) without intervention on DAS, due to unacceptably high-operative risk. In the year 2016, although the risk profile of patients increased, $53 \%$ of patients were referred for AVR, 22\% for TAVI and 3\% for balloon aortic valvuloplasty (BAV). Still, $22 \%$ of subjects were considered ineligible for DAS intervention and they were referred for OMT (Figure 2).

\section{Discussion}

The most important finding from our study is that in a period of just one decade, patients with DAS are currently referred for intervention at a more advanced stage of DAS. Whereas echocardiographic parameters of the AVA, mean-transvalvular pressure, and LVEF were similar in both groups, the prevalence of moderate-to-severe $\mathrm{PH}$, severe mitral insufficiency, or AF increased 3.1-, 8-, and 2.5-fold in patients evaluated recently for DAS. Both $\mathrm{PH}$ and $\mathrm{AF}$ independently increase perioperative risk and, additionally, $\mathrm{PH}$ has a negative impact on long-term outcome [21]. Furthermore, low-flow, low-gradient DAS was 
Table II. Echocardiographic findings in study participants

\begin{tabular}{|c|c|c|c|}
\hline Parameter & $\begin{array}{l}\text { DAS patients } 2005-2006 \\
(n=140)\end{array}$ & $\begin{array}{c}\text { DAS patients } 2016 \\
(n=152)\end{array}$ & $P$-value \\
\hline Left ventricle ejection fraction, mean \pm SD $(\%)^{* \#}$ : & $57.5 \pm 12.1$ & $55 \pm 12.1$ & 0.768 \\
\hline Median (Q1 : Q3) & $60(51: 65)$ & $60(50: 65)$ & \\
\hline LVEF $<50 \%, n(\%)$ & $26(18.6)$ & $28(18.4)$ & 0.974 \\
\hline Mean aortic gradient, mean \pm SD [mm Hg]: & $48.6 \pm 19.9$ & $46.2 \pm 15.6$ & 0.215 \\
\hline Median (Q1 : Q3) & $48(35: 61)$ & $46(37: 54)$ & \\
\hline Number of patients with MG > 40 mm Hg, $n(\%)$ & $97(69.3)$ & $95(62.5)$ & 0.222 \\
\hline Aortic valve area, mean $\pm \mathrm{SD}\left[\mathrm{cm}^{2}\right]$ & $0.87 \pm 0.3$ & $0.9 \pm 0.32$ & 0.356 \\
\hline Low-flow low-gradient DAS, $n$ (\%) & $7(6.4)$ & $18(11.8)$ & 0.037 \\
\hline \multicolumn{4}{|l|}{ Pulmonary hypertension, $n(\%)^{*}$ : } \\
\hline Moderate (RVSP: 31-55 mm Hg) & $8(5.7)$ & $33(21.7)$ & $<0.001$ \\
\hline Severe (RVSP > 55 mm Hg) & $4(2.9)$ & $8(5.3)$ & 0.300 \\
\hline Overall (RVSP $\geq 31$ mm Hg) & $12(8.6)$ & $42(27)$ & $<0.001$ \\
\hline \multicolumn{4}{|l|}{ Concomitant aortic valve insufficiency, $n(\%)^{*}$ : } \\
\hline Moderate & $12(8.6)$ & $20(13.1)$ & 0.210 \\
\hline Severe & $6(4.2)$ & $1(0.6)$ & 0.043 \\
\hline Overall & $18(12.8)$ & $21(13.7)$ & 0.801 \\
\hline Concomitant severe mitral valve stenosis, $n(\%)^{*}$ & $3(2.1)$ & $2(1.3)$ & 0.586 \\
\hline \multicolumn{4}{|l|}{ Concomitant mitral valve regurgitation, $n(\%)^{*}$ : } \\
\hline Moderate & $14(10)$ & $16(10.5)$ & 0.970 \\
\hline Severe & $1(0.7)$ & $9(5.9)$ & 0.015 \\
\hline Overall & $15(10.7)$ & $25(16.4)$ & 0.155 \\
\hline Ascending aorta diameter > $45 \mathrm{~mm}, n(\%)^{\#}$ & $5(3.5)$ & $6(3.9)$ & 0.866 \\
\hline
\end{tabular}

observed twice as often in 2016 as compared to 20052006. Therefore, patients with newly recognized DAS should undergo careful assessment using serial echocardiographic and stress tests. This would aid in optimally timing required interventions.

Thus, echocardiographic findings are valuable, being able to indicate high transvalvular gradient, massive and extensive calcifications, rapid disease progression, as well as atrium enlargement and right ventricular dysfunction [22]. Notably, the risk of intervention significantly increases with DAS progression. Furthermore, in asymptomatic or scarcely symptomatic patients, stress testing should be used to identify high-risk features including reduced exercise tolerance, exercise-induced symptoms, and absolute or relative hypotension [23].

In the present study, symptoms according to NYHA classification in classes 2 and higher were observed in $96.4 \%$ of the group I population and in $85 \%$ of patients with DAS in 2016. There is substantial controversy over the optimal timing of intervention for these patients, as some advocate early intervention while others favor conservative management until symptom onset [24].

On the one hand, sudden death risk in truly clinically asymptomatic patients with severe DAS was estimated at $1-1.5 \%$ per year [25], while intervention risk may exceed 3\% [11]. Thus, some experts would advocate a 'watchful waiting' attitude. However, we have demonstrated that the policy of 'watchful waiting' until symptoms (arrhythmias, pulmonary hypertension or congestive heart failure) appear in higher classes should be reconsidered carefully, as this leads to high perioperative mortality scores in patients. In our study, at the point of invasive DAS management, EuroSCORE II and STS scores of $4 \%$ or higher were present in $26-27 \%$ of patients, as compared to $6-7 \%$ in $2005-2006$.

This is in line with other observational studies indicating that the 'watchful waiting' attitude leads to advanced patient age and the increasing number of 
Table III. Comorbidities included in STS score and EuroSCORE II

\begin{tabular}{|c|c|c|c|}
\hline Parameter & $\begin{array}{l}\text { DAS patients } 2005-2006 \\
\qquad(n=140)\end{array}$ & $\begin{array}{c}\text { DAS patients } 2016 \\
(n=152)\end{array}$ & $P$-value \\
\hline Severe chronic lung disease, $n(\%)^{\star \#}$ & $3(2.1)$ & $26(17.1)$ & $<0.001$ \\
\hline Renal dysfunction (eGFR $<60), n(\%)^{\star *}$ & $32(22.8)$ & $53(34.9)$ & 0.024 \\
\hline Extracardiac arteriopathy (carotid or PAD), $n(\%)^{* \#}$ & $25(17.8)$ & $61(40.1)$ & $<0.001$ \\
\hline Atrial fibrillation, $n(\%)^{*}$ & $16(11.4)$ & $41(27)$ & 0.001 \\
\hline Previous ischemic stroke/TIA, $n(\%)^{*}$ & $8(5.7)$ & $17(11.2)$ & 0.095 \\
\hline Significant coronary artery disease (> 50\%), $n(\%)^{*}$ & $59(42.1)$ & $71(46.7)$ & 0.433 \\
\hline Previous MI, $n(\%)^{* \#}$ : & $12(8.6)$ & $25(16.4)$ & 0.043 \\
\hline$<21$ days before intervention & $0(0)$ & $0(0)$ & N/A \\
\hline$\leq 90$ days before intervention & $0(0)$ & $6(3.95)$ & 0.049 \\
\hline Previous $\mathrm{PCI}, n(\%)^{*}$ & $6(9.2)$ & $39(25.6)$ & $<0.001$ \\
\hline Previous cardiac surgery, $n(\%)^{\star \#}$ & $5(3.7)$ & $8(5.3)$ & 0.484 \\
\hline \multicolumn{4}{|l|}{ Intervention urgency, $n(\%)$ : } \\
\hline Elective*\# $^{* \#}$ & $137(98)$ & $141(92.76)$ & 0.042 \\
\hline Urgent*\# & $1(0.7)$ & $9(5.92)$ & 0.015 \\
\hline Emergency*\# & $2(1.4)$ & $2(1.32)$ & 0.933 \\
\hline Shock/Critical preoperative status, $n(\%)^{\star \#}$ & $1(0.7)$ & $4(2.63)$ & 0.207 \\
\hline Active endocarditis, $n(\%)^{\star \#}$ & $0(0)$ & $0(0)$ & $\mathrm{N} / \mathrm{A}$ \\
\hline Immunocompromised, $n(\%)^{\star}$ & $1(0.7)$ & $6(3.95)$ & 0.071 \\
\hline Poor mobility, $n$ (\%)\# & $8(5.7)$ & $13(8.6)$ & 0.348 \\
\hline
\end{tabular}

*Parameters included in STS score, "parameters included in EuroSCORE II.
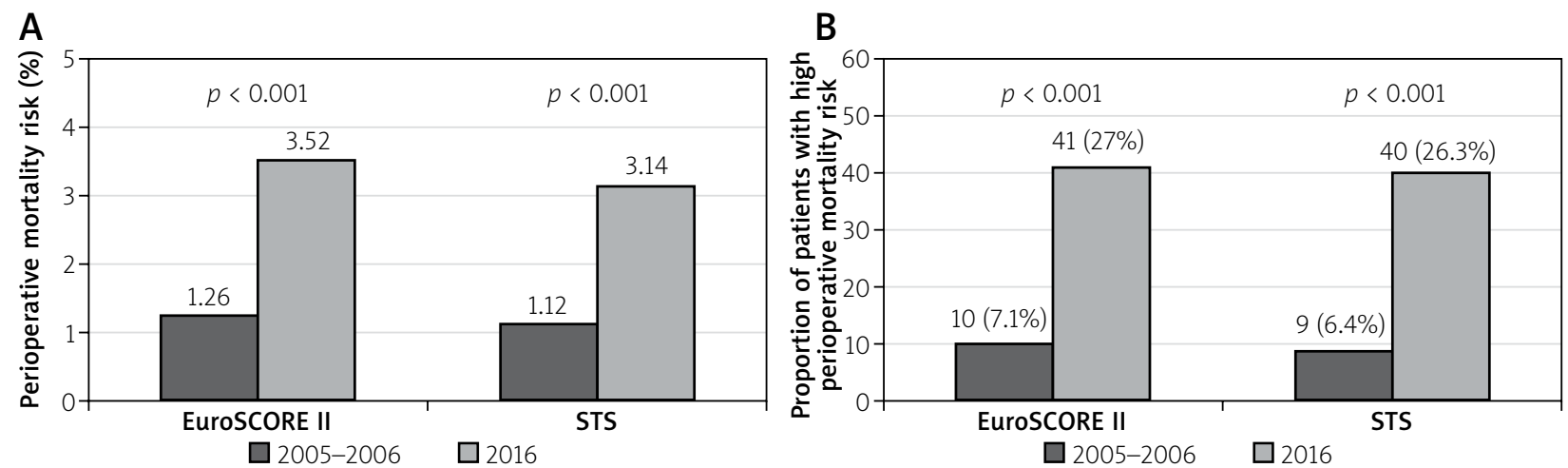

Figure 1. A - Comparison of mean EuroSCORE II and STS scores in group I and group II, B - prevalence of patients with high risk of perioperative mortality STS and EuroSCORE $>4 \%$

concomitant comorbidities which increase STS and EuroSCORE II risk $[12,13]$.

Furthermore, Genereux et al. found in a meta-analysis of 4 retrospective studies that patients with severe asymptomatic DAS have a 3.5-fold higher rate of all-cause death when managed with a conservative strategy compared to AVR [22]. Moreover, this meta-analysis favors intervention over optimal medical treatment in terms of cardiovascular risk reduction, e.g. sudden cardiac death [22].
We observed in our present study that currently, as compared to $2005 / 2006$, there are fewer patients with DAS and symptoms of congestive heart failure; however, these patients have higher scores using the EuroSCORE II and STS calculators. This is due to a significant increase in the prevalence of associated cardiovascular risk factors and vital comorbidities such as lung disease, peripheral artery occlusive disease, and disabling stroke in recently admitted patients with DAS. The results from our 
A

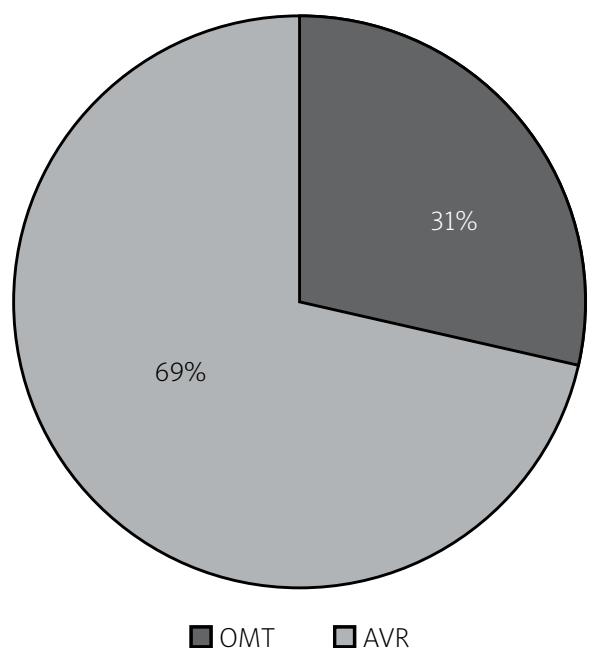

B

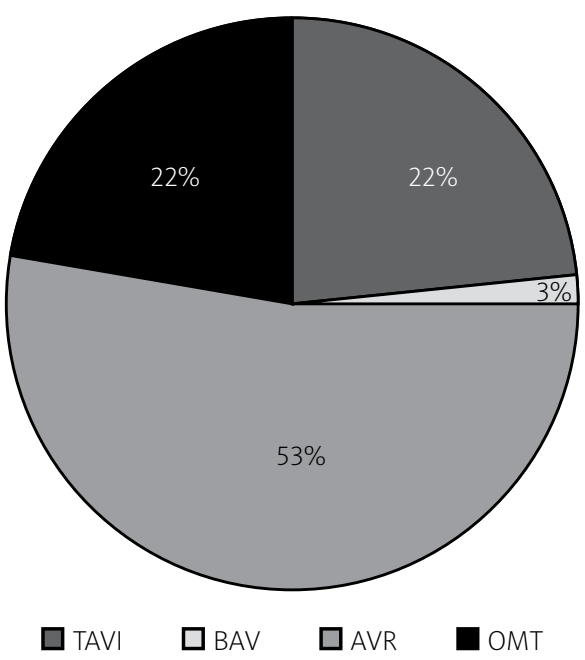

Figure 2. A - Patients referred for aortic valve replacement (AVR) or optimal medical treatment (OMT) in 2005-2006. B - Patients referred for AVR, OMT, transcatheter aortic valve replacement (TAVI) and balloon aortic valvuloplasty (BAV) in 2016

study are in line with recent epidemiological data which show changes in the profile of patients with valvular disease who attend clinics, wards and emergency units [6, 8, 26-28]. Hypertension, diabetes, peripheral artery disease, renal dysfunction and chronic pulmonary disease have a huge influence on perioperative risk $[12,13,26]$.

Another problem arises with symptomatic patients with DAS referred for intervention. Patient mortality increases dramatically with appearance of symptoms [29], exceeding $60 \%$ during the 5 years after the time of first hospital admission [27]. Cardiac deaths represent more than half of cases, with heart failure and sudden death as the main causes [30]. In patients over 80 years prognosis is even poorer, and the annual mortality reaches up to $50 \%$ [31].

For 15 years, transcatheter aortic valve replacement (TAVI) has been a viable alternative to surgical aortic valve replacement (AVR) for high-surgical-risk subjects [27]. Data from recent trials suggest that performing TAVI in subjects with intermediate periprocedural risk (STS below 4\%) may be beneficial and have comparable periprocedural mortality results [32]. However, in patients with DAS and low-to-intermediate periprocedural risk, the primary endpoint of all-cause mortality, stroke, or MI was relatively high at 5 years $(39.2 \%$ among TAVI-treated patients and $35.8 \%$ in AVR-treated patients, $p=N S)$. Notably, the principal concerns regard the high rates of pacemaker implantation (about $40 \%$ of patients) and paravalvular leaks (about 21\%) in the TAVI-treated patients [33, 34]. Nevertheless, as we face increasing periprocedural mortality risk in patients referred for AVR, the proportion of patients referred for TAVI will naturally increase [35]. Our current study indicates that although there is an increase in the risk profile of patients currently admitted, increased access to invasive treatment op- tions, such as TAVI and AVR, leads to intervention in 78\% of patients. Still, $22 \%$ of subjects in 2016 , as compared to $30 \%$ in $2005-2006$, were considered ineligible for DAS intervention and were referred for OMT.

\section{Study limitations}

The first limitation is that the present study is derived from data of one center, based on a population subset consisting predominantly of symptomatic patients with DAS admitted for intervention. The population of asymptomatic patients with DAS was underrepresented.

Another study limitation is a lack of data concerning intervention outcomes, which could present a real perioperative risk comparison between both groups. Because of this, therapeutic decisions in 2005-2006 cannot be directly extrapolated to currently available guidelines and therapeutic options. Moreover, TAVI was not available in 2005-2006 as a standard procedure. Perioperative risk assessment was performed in 2005-2006 using the old "logistic" EuroSCORE, which is not compatible with the currently used EuroSCORE II. We cannot indicate the proportion of patients in both study periods who were a priori disqualified from even referral for the assessment for potential intervention and a priori deemed "too high risk" by their GP.

\section{Conclusions}

Within one decade, the risk profile of patients admitted with DAS has significantly increased, which is mainly due to the accumulation of comorbidities in advanced age and more advanced disease at presentation. Although new treatment methods such as TAVI have expanded the indications for intervention in high-risk patients, the number of patients disqualified from interventional treatment remains high. 
A careful diagnostic and qualification process in patients with DAS is crucial for obtaining the best results and reducing the risk. The referral for intervention of DAS should be considered earlier than current recommendations, preferably before echocardiographic features of decompensated DAS and symptoms of heart failure occur.

\section{Acknowledgments}

Jakub Baran and Jakub Podolec contributed equally.

\section{Conflict of interest}

The authors declare no conflict of interest.

\section{References}

1. Eveborn GW, Schirmer H, Heggelund G, et al. The evolving epidemiology of valvular aortic stenosis. The Troms $\varnothing$ Study. Heart 2013; 99: 396-400.

2. Nkomo VT, Gardin JM, Skelton TN. Burden of valvular heart diseases: a population based study. Lancet 2006; 368: 1005-11.

3. Vahanian A, Alfieri O, Andreotti F, et al. Guidelines on the management of valvular heart disease (version 2012): The Joint Task Force on the Management of Valvular Heart Disease of the European Society of Cardiology (ESC) and the European Association for Cardio Thoracic Surgery (EACTS). Eur Heart J 2012; 33: 2451-96.

4. Ramos J, Monteagudo JM, González-Alujas T, et al. Large-scale assessment of aortic stenosis: facing the next cardiac epidemic? Eur Heart J Cardiovasc Imaging 2017; doi: 10.1093/ehjci/jex223.

5. lung B, Vahanian A. Degenerative calcific aortic stenosis: a natural history. Heart 2012; 98 Suppl 4: iv7-13.

6. Danielsen R, Aspelund T, Harris TB, et al. The prevalence of aortic stenosis in the elderly in Iceland and predictions for the coming decades: the AGES-Reykjavik study. Int I Cardiol 2014; 176: 916-22.

7. Tastet L, Simard L, Clavel MA. Severe and asymptomatic aortic stenosis management challenge: knowing that we do not really know. Curr Treat Options Cardiovasc Med 2017; 19: 33.

8. Pohle K, Mäffert R, Ropers D, et al. Progression of aortic valve calcification: association with coronary atherosclerosis and cardiovascular risk factors. Circulation 2001; 104: 1927-32.

9. Peeters F, Meex S, Dweck MR, et al. Calcific aortic valve stenosis: hard disease in the heart: a biomolecular approach towards diagnosis and treatment. Eur Heart J 2018; 39: 2618-24.

10. Généreux P, Pibarot P, Redfors B, et al. Staging classification of aortic stenosis based on the extent of cardiac damage. Eur Heart J 2017; 38: 3351-8.

11. Baumgartner H, Falk V, Bax J, et al. Guidelines for the management of valvular heart disease. Kardiol Pol 2018; 76: 1-62.

12. Nashef SAM, Roques F, Sharples LD, et al. EuroSCORE II. Eur J Cardiothorac Surg 2012; 41: 734-44.

13. O'Brien SM, Shahian DM, Filardo G, et al. The Society of Thoracic Surgeons 2008 cardiac surgery risk models: part 2 - isolated valve surgery. Ann Thorac Surg 2009; 88: S23-42.

14. Shahian DM, O'Brien SM, Filardo G, et al. The Society of Thoracic Surgeons 2008 cardiac surgery risk models: part 3 - valve plus coronary artery bypass grafting surgery. Ann Thorac Surg 2009; 88: S43-62.

15. Taniguchi T, Morimoto T, Shiomi H, et al. Prognostic impact of left ventricular ejection fraction in patients with severe aortic stenosis. JACC Cardiovasc Interv 2018; 11: 145-57.

16. Baumgartner $\mathrm{H}$, Hung J, Bermejo J, et al. Recommendations on the echocardiographic assessment of aortic valve stenosis: a focused update from the European Association of Cardiovascular Imaging and the American Society of Echocardiography. J Am Soc Echocardiogr 2017; 30: 372-92.

17. Podolec J, Baran J, Niewiara $九$, et al. The role of biomarkers as an alternative and completion of the diagnostic and therapeutic pathway in patients with aortic stenosis. J Rare Card Dis 2016; 2: $1-1$.

18. Bluth El, Stavros AT, Marich KW, et al. Carotid Duplex sonography: a multicenter recommendation for standardized imaging and Doppler criteria. Radiographics 1988; 8: 487-506.

19. Kablak-Ziembicka A, Przewlocki T, Tracz W, et al. Prognostic value of carotid intima-media thickness in detection of coronary atherosclerosis in patients with calcified aortic valve stenosis. J Ultrasound Med 2005; 24: 461-7.

20. Kabłak-Ziembicka A, Przewłocki T, Hlawaty M, et al. Internal carotid artery stenosis in patients with degenerative aortic stenosis. Kardiol Pol 2008; 66: 837-42.

21. Levy F, Bohbot $\mathrm{Y}$, Sanhadji K, et al. Impact of pulmonary hypertension on long-term outcome in patients with severe aortic stenosis. Eur Heart J Cardiovasc Imaging 2018; 19: 553-61.

22. Genereux P, Stone GW, O'Gara PT, et al. Natural history, diagnostic approaches, and therapeutic strategies for patients with asymptomatic severe aortic stenosis. J Am Coll Cardiol 2016; 67: 2263-88.

23. Das P, Rimington H, Chambers J. Exercise testing to stratify risk in aortic stenosis. Eur Heart J 2005; 26: 1309-13.

24. Maréchaux S, Hachicha Z, Bellouin A, et al. Usefulness of exercise-stress echocardiography for risk stratification of true asymptomatic patients with aortic valve stenosis. Eur Heart J 2010; 31: 1390-7.

25. Pellikka PA, Sarano ME, Nishimura RA, et al. Outcome of 622 adults with asymptomatic, hemodynamically significant aortic stenosis during prolonged follow-up. Circulation 2005; 111: 3290-5.

26. lung B, Baron G, Butchart EG, et al. A prospective survey of patients with valvular heart disease in Europe: the Euro Heart Survey on Valvular Heart Disease. Eur Heart J 2003; 24: 1231-43.

27. Bonow RO, Greenland P. Population wide trends in aortic stenosis incidence and outcomes. Circulation 2015; 131: 969-71.

28. Bobrowska B, Zasada W, Dziewierz A, et al. Comparison of demographics, cardiovascular risk factors profile and prevalence of coexistent atherosclerotic vascular disease in patients with severe aortic stenosis stratified according to dichotomized stenosis severity. Adv Interv Cardiol 2017; 13: 331-4.

29. Berry C, Lloyd SM, Wang Y, et al. The changing course of aortic valve disease in Scotland: temporal trends in hospitalizations and mortality and prognostic importance of aortic stenosis. Eur Heart J 2013; 34: 1538-47.

30. Minamino-Muta E, Kato T, Morimoto T, et al. Causes of death in patients with severe aortic stenosis: an observational study. Sci Rep 2017; 7: 14723.

31. Ben-Dor I, Pichard AD, Gonzalez MA, et al. Correlates and causes of death in patients with severe symptomatic aortic stenosis 
who are not eligible to participate in a clinical trial of transcatheter aortic valve implantation. Circulation 2010; 122: 37-42.

32. Thyregod HG, Steinbruchel DA, Ihlemann N, et al. Transcatheter versus surgical aortic valve replacement in patients with severe aortic valve stenosis: 1-year results from the All-Comers NOTION randomized clinical trial. J Am Coll Cardiol 2015; 65: 2184-94.

33. Witberg G, Lador A, Yahav D, Kornowski R. Transcatheter versus surgical aortic valve replacement in patients at low surgical risk: a meta-analysis of randomized trials and propensity score matched observational studies. Catheter Cardiovasc Interv 2018 Feb 1 Epub ahead of print; doi: 10.1002/ccd.27518.

34. Khan SU, Lone AN, Saleem MA, et al. Transcatheter vs surgical aortic-valve replacement in low- to intermediate-surgical-risk candidates: a meta-analysis and systematic review. Clin Cardiol 2017; 40: 974-81.

35. Parma R, Dąbrowski M, Ochała A, et al. The Polish Interventional Cardiology TAVI Survey (PICTS): adoption and practice of transcatheter aortic valve implantation in Poland. Adv Interv Cardiol 2017; 13: 10-7. 